\title{
CARD15 mutations and colorectal cancer in a South European country
}

\author{
Paulo Freire • Francisco Portela • Maria M. Donato • Pedro Figueiredo • \\ Manuela Ferreira • Pedro Amaro • Anabela Sá • Paulo Andrade • Hermano Gouveia • \\ Carlos Sofia
}

Accepted: 20 July 2010 /Published online: 30 July 2010

(C) Springer-Verlag 2010

\begin{abstract}
Purpose CARD15 mutations are associated with higher susceptibility to Crohn's disease (CD) and longstanding colonic $\mathrm{CD}$ increases the risk of developing colorectal cancer (CRC). The relation between these mutations and sporadic CRC remains controversial. The aim of this study was to assess whether germline and/or somatic CARD15 mutations are risk factors for sporadic CRC in Portugal and whether there are genotype-phenotype correlations in these patients.

Methods The three main CARD15 mutations (R702W, G908R and 3020insC) were researched in 112 sporadic CRC patients and 152 healthy subjects.

Results Overall, CARD15 mutations were found in 18 patients $(16.1 \%)$ and in 15 controls $(9.9 \% ; p=0.132)$. Individually, the incidence of R702W was significantly higher in patients than in controls $(12.5 \%$ vs. $5.3 \%, p=$ $0.035)$, whereas the genotype frequencies for G908R $(2.7 \%$ vs. $3.3 \%)$ and $3020 \mathrm{ins}$ C (0.9\% vs. $1.3 \%)$ were not
\end{abstract}

P. Freire $(\bowtie) \cdot$ F. Portela $\cdot$ P. Figueiredo $\cdot$ M. Ferreira $\cdot$ P. Amaro $\cdot$

P. Andrade $\cdot$ H. Gouveia $\cdot$ C. Sofia

Department of Gastroenterology, Coimbra University Hospital,

Avenida Bissaya Barreto,

3000-076 Coimbra, Portugal

e-mail: pauloavfreire@gmail.com

F. Portela

e-mail: fasportela@gmail.com

P. Figueiredo

e-mail: pedro.n.figueiredo@clix.pt

M. Ferreira

e-mail: malvesferreira@netcabo.pt

P. Amaro

e-mail: pedro.amaro67@sapo.pt

P. Andrade

e-mail: paulo_andrade@sapo.pt statistically different between the two groups. Entire genotypic agreement was found in patients genotyped for blood and neoplastic DNA. A significantly higher incidence of CARD 15 mutations was detected in patients with CRC diagnosed under 60 years old $(28.6 \%$ vs. $10.4 \%, p=$ $0.015)$ and in female patients $(24.4 \%$ vs. $10.4 \%, p=$ 0.048). No associations were found between CARD15 mutations and family history, symptoms or CRC pathologic characteristics.

Conclusions The CARD15 R702W variant might be a predisposing factor to sporadic CRC in Portugal, particularly in patients under 60-years old and in female patients. This susceptibility appears to be linked with germline CARD15 mutations. Nevertheless, we have found no evidence that $C A R D 15$ mutations predict the pathologic characteristics of CRC.

Keywords Colorectal cancer $\cdot$ CARD15 - Inflammation . Susceptibility

H. Gouveia

e-mail: hermanogouveia@netcabo.pt

C. Sofia

e-mail: carlossofia@huc.min-saude.pt

M. M. Donato $\cdot$ P. Figueiredo $\cdot$ C. Sofia

Department of Gastroenterology,

Coimbra University Medical Faculty,

Avenida Bissaya Barreto,

3000 Coimbra, Portugal

M. M. Donato

e-mail: mariamanueldonato@gmail.com

A. Sá

Department of Oncology, Coimbra University Hospital,

Avenida Bissaya Barreto,

3000 Coimbra, Portugal

e-mail: huc@min-saude.pt 


\section{Introduction}

In developed countries, colorectal cancer (CRC) is one of the most frequent malignancies and is the second most common cause of malignant deaths, preceded only by lung cancer [1, 2]. The incidence of CRC in Portugal was 77 new cases per 100,000 inhabitants in 2006, one of the highest in the Western world [3].

Germline mutations in tumour-suppressor adenomatous polyposis coli genes and DNA mismatch repair genes lead to the recognised familial adenomatous polyposis related CRC and hereditary non-polyposis CRC, respectively [4]. These inherited cases account for about $5-10 \%$ of CRC [4]. Excluding inherited types of CRC, the susceptibility of a particular individual to developing sporadic CRC remains largely undetermined. Nevertheless, the pathogenesis of sporadic CRC is thought to be multifactorial, involving multiple genetic and various environmental factors [5-7].

Bacterial flora keeps the normal colon mucosa in a continuous state of low-grade inflammation, stimulating the release of various pro-inflammatory cytokines by the immune cells [8]. Several epidemiological and biological data support a clear association between chronic inflammation and cancer [9]. Typical examples are the causal connection between Helicobacter pylori-induced chronic gastritis and the development of mucosal-associated lymphoid tissue (MALT) B cell lymphoma and/or gastric cancer [10], as well as the association between longstanding inflammatory bowel disease (IBD) and CRC [11]. In fact, it is estimated that up to $15 \%$ of all IBD patients will develop CRC [11]. Furthermore, precursor CRC lesions may often have inflammatory histological features $[8,12]$ and pro-inflammatory genes have been shown to be important in the maintenance and progression of CRC [13]. In addition, inflammation may favour tumourigenesis by inducing DNA damage [14, 15], stimulating continuous cell proliferation $[16,17]$ and arousing angiogenesis [18]. Finally, regular use of nonsteroidal anti-inflammatory drugs, such as aspirin, exhibits chemoprevention effect of CRC [19].

How the increased risk of CRC in IBD patients is mediated remains undefined. Nevertheless it is thought to involve genes linked to the inflammatory response, which result in the activation of neutrophils and the consequent generation of significant amounts of reactive oxygen species [20]. The continuous exposure of the gastrointestinal epithelium to reactive oxygen species is believed to be associated with an amplified mutation rate, which results in an increased likelihood of tumour development [20]. Thus, assuming that the underlying chronic inflammation in IBD is involved in the progression of CRC, genetic factors implicated in the chronic inflammatory process of IBD may simultaneously predispose patients without IBD to CRC.
There is strong evidence that CARD15 mutations increase susceptibility to Crohn's disease (CD) [21-25]. Hence, the possible association of CARD15 mutations with sporadic CRC has been studied recently in Polish, Greek, Finnish, New Zealand, Hungarian and German Caucasian CRC patients, but the results have been controversial (Table 1) [26-32]. Furthermore, almost all of these studies only assessed CARD15 mutations in DNA extracted from blood or nonneoplastic tissue, i.e. involving only research of germline mutations [26, 27, 29-32]. Clarifying the potential involvement of CARD15 somatic mutations in the pathogenesis of $\mathrm{CRC}$ also requires investigation in the neoplastic tissue. Therefore, at this stage, the role of CARD15 variants in the development of CRC remains unclear. In light of these findings, and given that the frequency of CARD15 mutations varies in different populations, our aim was to investigate whether germline and/or somatic CARD15 mutations increased susceptibility to sporadic CRC in Portugal, a country with a high incidence and mortality associated with this disease. Additionally, we intended to investigate whether there are genotype-phenotype correlations in these patients.

\section{Methods}

\section{Patients}

One hundred and twelve consecutive Portuguese patients with $\mathrm{CRC}$ and without a previous diagnosis of IBD or any of the known hereditary cancer syndromes (male/female: 67/45; mean age at diagnosis of CRC $64.3 \pm 9.9$ years old) and 152 healthy (cancer-free blood donors) sex-matched controls, drawn from the central region of Portugal, were genotyped for the three main CARD15 mutations. Genomic DNA was isolated from whole blood in all the study participants and in 14 CRC patients it was also isolated from neoplastic biopsy specimens.

The vast majority of the group studied consisted of truly sporadic cases (95 patients, $84.8 \%$ ), whilst 17 patients (15.2\%) reported a history of CRC in at least one first-degree relative.

Comprehensive clinical data, including age and symptoms at diagnosis and the clinicopathologic characteristics of the tumour, were collected from each patient.

The research was approved by the local Ethics Committee and informed consent was obtained from all participants prior to enrolment into the study, in accordance with the Declaration of Helsinki.

Sample DNA extraction and genotyping

Genomic DNA was isolated from whole blood and biopsy specimens in accordance with the QIAamp Mini Kit (QIAGEN GmbH, Germany). 
Table 1 CARD15 and colorectal cancer: summary of association analyses

\begin{tabular}{|c|c|c|c|c|c|c|c|c|c|}
\hline & \multirow{2}{*}{$\begin{array}{l}\text { Country } \\
\text { [Reference] }\end{array}$} & \multicolumn{2}{|c|}{ Poland [26] } & \multirow{2}{*}{$\begin{array}{l}\text { Greece } \\
{[27]}\end{array}$} & \multirow{2}{*}{$\begin{array}{l}\text { Finnland } \\
{[28,29]}\end{array}$} & \multirow{2}{*}{$\begin{array}{l}\text { New Zealand } \\
{[30]}\end{array}$} & \multirow{2}{*}{$\begin{array}{l}\text { Hungary } \\
{[31]}\end{array}$} & \multicolumn{2}{|c|}{ Germany [32] } \\
\hline & & $\leq 50$ years $^{\mathrm{a}}$ & $>50$ years $^{\mathrm{a}}$ & & & & & Total & $\leq 50$ years $^{\mathrm{a}}$ \\
\hline & CRC $(n)$ & 50 & 250 & 104 & $953 / 960 / 926^{\mathrm{c}}$ & 133 & 194 & 1044 & 143 \\
\hline & Controls $(n)$ & 300 & 300 & 100 & $508 / 508 / 348^{c}$ & 201 & 200 & 724 & 724 \\
\hline \multicolumn{10}{|l|}{$\mathrm{R} 702 \mathrm{~W}$} \\
\hline CRC & $\begin{array}{l}\% \text { Allele } \\
\text { frequency }\end{array}$ & - & - & 4.8 & 2.2 & 7.1 & 1.8 & 5.1 & 7.7 \\
\hline \multirow[t]{2}{*}{ Control } & $\begin{array}{l}\% \text { Allele } \\
\text { frequency }\end{array}$ & - & - & 1.0 & 2.1 & 3.0 & 1.5 & 4.6 & 4.6 \\
\hline & $p$ value & - & - & 0.02 & 0.88 & 0.03 & 0.78 & 0.5 & 0.03 \\
\hline \multicolumn{10}{|l|}{ G908R } \\
\hline CRC & $\begin{array}{l}\% \text { Allele } \\
\text { frequency }\end{array}$ & - & - & 8.65 & 0.3 & 2.2 & 1.8 & 1.5 & 2.1 \\
\hline \multirow[t]{2}{*}{ Control } & $\begin{array}{l}\% \text { Allele } \\
\text { frequency }\end{array}$ & - & - & 3.5 & 0.2 & 0.8 & 1.8 & 1.2 & 1.2 \\
\hline & $p$ value & - & - & 0.025 & 0.57 & 0.09 & 0.95 & 0.43 & 0.36 \\
\hline \multicolumn{10}{|l|}{ 3020insC } \\
\hline CRC & $\begin{array}{l}\% \text { Allele } \\
\text { frequency }\end{array}$ & $2^{\mathrm{b}}$ & $14.4^{\mathrm{b}}$ & 12.5 & 1.9 & 2.2 & 3.6 & 3.6 & 3.8 \\
\hline \multirow[t]{2}{*}{ Control } & $\begin{array}{l}\% \text { Allele } \\
\text { frequency }\end{array}$ & $7^{\mathrm{b}}$ & $7^{\mathrm{b}}$ & 6 & 1.9 & 1.0 & 2.5 & 2.8 & 2.8 \\
\hline & $p$ value & 0.3010 & 0.0046 & 0.017 & 0.96 & 0.19 & 0.40 & 0.17 & 0.32 \\
\hline \multicolumn{10}{|c|}{$\mathrm{R} 702 \mathrm{~W} / \mathrm{G} 908 \mathrm{R} / 3020 \mathrm{insC}$} \\
\hline $\mathrm{CRC}$ & $\begin{array}{l}\% \text { Genotype } \\
\text { frequency }\end{array}$ & - & - & 51.9 & - & 21.8 & 14.4 & 10.2 & 25.2 \\
\hline \multirow[t]{2}{*}{ Control } & $\begin{array}{l}\% \text { Genotyple } \\
\text { frequency }\end{array}$ & - & - & 21.0 & - & 8.9 & 11.5 & 8.6 & 8.6 \\
\hline & $p$ value & - & - & $<0.0001$ & - & 0.001 & 0.45 & 0.10 & 0.038 \\
\hline
\end{tabular}

$C R C$ colorectal cancer

${ }^{a}$ Age at diagnosis of CRC

${ }^{\mathrm{b}}$ Genotype frequencies of carriership of mutant allele

${ }^{\mathrm{c}}$ In the investigation of R702W, G908R and 3020insC were utilised 953, 960 and $926 \mathrm{CRC}$ cases and 508, 508 and 348 controls, respectively

All participants were genotyped for the three major $C A R D 15$ mutations: R702W (SNP8), G908R (SNP12) and 3020insC (SNP13). Genotyping was performed by real-time polymerase chain reaction (PCR): variants $\mathrm{R} 702 \mathrm{~W}$ and G908R using HybProbe (FRET) and 3020insC variant using SimpleProbe. The R702W variant was amplified and detected using the forward primer 5'-AgCCgCACAACCTTAgATCAC-3', the reverse primer 5'-gCgggCACAggCATAgC-3', the anchor probe 5'-LC Red640-gTCTggCACTCAgCCAgCAggCCCC$\mathrm{PH}$ and the donor probe 5'-gCgCCAgAgCAgggCCTTCTCAFL. For assay of the G908R mutation, 5'-gCACATATCAggTA CTCACTgACACT-3' was used as the forward primer, 5'-TTA CCTgAgCCACCTCAAgC-3' as the reverse primer, 5'-LC Red705-CTgAAAAggCCAAAAgAgTCAACAgAC-PH as the anchor probe and the 5'-CCACTCTgTTgCCCCAgAA-FL as the donor probe. In order to detect the 3020insC variant, PCR was carried out using the forward primer 5'-gACAgg TgggCTTCAgTAgA-3', the reverse primer 5'-TgAggTTCggA gAgCTAAAACAg-3' and the simple probe 5'-CTgCAggCCC CTTgAAAg-FLQ.
The reaction mixture consisted of $18 \mu$ of the PCR master mix plus $2 \mu \mathrm{l}$ of the DNA of each patient. The PCR master mix for the $\mathrm{R} 702 \mathrm{~W}$ variant included $5.0 \mathrm{mM}$ $\mathrm{MgCl}_{2}, 1 \times$ LightCycler DNA master hybridization probes (Roche, Mannheim, Germany), $0.5 \mu \mathrm{M}$ each primer and $0.1 \mu \mathrm{M}$ each fluorescein and LC-Red-640-labelled probe. Cycling parameters consisted of one cycle of $95^{\circ} \mathrm{C}$ for $2 \mathrm{~min}$, followed by amplification for 45 cycles of $95^{\circ} \mathrm{C}$ for $0 \mathrm{~s}, 55^{\circ} \mathrm{C}$ for $10 \mathrm{~s}$, and $72^{\circ} \mathrm{C}$ for $5 \mathrm{~s}$. A melting curve was created by measuring the fluorescent signal generated with the following profile: $95^{\circ} \mathrm{C}$ for $5 \mathrm{~s}, 50^{\circ} \mathrm{C}$ for $10 \mathrm{~s}$, and $90^{\circ} \mathrm{C}$ for $0 \mathrm{~s}$ with a slope $0.4^{\circ} \mathrm{C} / \mathrm{s}$ transition. The PCR master mix for the G908R mutation included $2.5 \mathrm{mM} \mathrm{MgCl}_{2}, 1 \times$ LightCycler DNA master hybridization probes (Roche, Mannheim, Germany), $0.5 \mu \mathrm{M}$ each primer and $0.2 \mu \mathrm{M}$ each fluorescein and LC-Red-705-labelled probe. Cycling parameters consisted of one cycle of $95^{\circ} \mathrm{C}$ for $2 \mathrm{~min}$, followed by amplification for 40 cycles of $95^{\circ} \mathrm{C}$ for $10 \mathrm{~s}$, $57^{\circ} \mathrm{C}$ for $8 \mathrm{~s}$, and $72^{\circ} \mathrm{C}$ for $17 \mathrm{~s}$. A melting curve was originated by measuring the fluorescent signal generated 
with the following profile: $95^{\circ} \mathrm{C}$ for $20 \mathrm{~s}, 40^{\circ} \mathrm{C}$ for $20 \mathrm{~s}$, and $85^{\circ} \mathrm{C}$ for $0 \mathrm{~s}$ with a slope $0.2^{\circ} \mathrm{C} / \mathrm{s}$ transition. Finally, the PCR master mix for the 3020 insC variant included $2.5 \mathrm{mM}$ $\mathrm{MgCl}_{2}, 1 \times$ LightCycler DNA master hybridization probes (Roche, Mannheim, Germany), $0.2 \mu \mathrm{M}$ forward primer, $0.5 \mu \mathrm{M}$ reverse primer and $0.2 \mu \mathrm{M}$ simple probe. Cycling parameters consisted of 1 cycle of $95^{\circ} \mathrm{C}$ for $2 \mathrm{~min}$, followed by amplification for 40 cycles of $95^{\circ} \mathrm{C}$ for $10 \mathrm{~s}$, $55^{\circ} \mathrm{C}$ for $10 \mathrm{~s}$, and $72^{\circ} \mathrm{C}$ for $20 \mathrm{~s}$. A melting curve was created by measuring the fluorescent signal generated with the following profile: $95^{\circ} \mathrm{C}$ for $20 \mathrm{~s}, 40^{\circ} \mathrm{C}$ for $20 \mathrm{~s}$, and $85^{\circ} \mathrm{C}$ for $0 \mathrm{~s}$ with a slope $0.2^{\circ} \mathrm{C} / \mathrm{s}$ transition. Sterile water was used as a negative control. The change of fluorescence was converted to a melting peak (Tm) by plotting the negative derivative of the fluorescent signal corresponding to the temperature $(-\mathrm{dF} / \mathrm{dT})$ with the LightCycler software.

The sequence variations of the PCR products were confirmed by DNA sequencing.

\section{Statistical analysis}

The significance of the differences in CARD15 genotype frequencies between CRC patients and controls, as well as the association of CARD15 variants with the clinicopathologic characteristics, were assessed using $\chi^{2}$ tests. Odds ratios (OR) were determined with the corresponding $\chi^{2}$ distribution test and $95 \%$ confidence intervals $(95 \%$ CI).

Survival and recurrence cumulative curves as a function of time were produced utilising the Kaplan-Meier approach and compared with the log-rank test.

Only $p$ values $<0.05$ were considered significant.

Each genetic variant studied was in Hardy-Weinberg equilibrium.
The data was analysed using the Statistical Package for Social Sciences-SPSS (SPSS Inc., Chicago, Illinois, USA) computer software for Windows (version 17.0).

\section{Results}

The combined genotype frequency of R702W/G908R/ 3020insC was not statistically different between CRC patients and controls $(16.1 \%$ vs. 9.9\%, $p=0.132$; OR, 1.75; 95\% CI, 0.84-3.64; Table 2). Individually, R702W was significantly more frequent in the CRC patients than the controls $(12.5 \%$ vs. $5.3 \%, p=0.035$; OR, $2.57 ; 95 \% \mathrm{CI}$, 1.04-6.36), whereas comparable genotypic frequencies of G908R and 3020insC were observed in both groups (Table 2). Among subjects with CARD15 mutations, only one patient was homozygous for R702W, whilst all the others were heterozygous for a particular mutation (Table 2). No compound heterozygous carriers were identified.

In the 14 patients genotyped for CARD15 mutations with DNA isolated from whole blood and also with DNA isolated from neoplastic biopsy specimens, complete genotypic agreement was found between the two samples, namely two patients heterozygous for $\mathrm{R} 702 \mathrm{~W}$ and the remaining 12 wild-type homozygous.

At least one variant of the CARD15 was detected in ten $(28.6 \%)$ of the 35 patients with CRC diagnosed under 60 years old and in eight $(10.4 \%)$ of the 77 patients with $\geq 60$ years old at diagnosis of CRC ( $p=0.015$; OR, 3.45; 95\% CI, 1.22-9.72; Table 3). Female CRC patients were more likely to carry a CARD15 mutation than their male counterparts $(24.4 \%$ vs. $10.4 \%, p=0.048$; OR, 2.77; 95\% CI, 0.98-7.82; Table 3). In contrast, patients having at least one first-degree relative diagnosed with $\mathrm{CRC}$ were no more likely to carry a CARD15 mutation than patients
Table 2 Genotype frequencies of the CARD15 variants in CRC patients and controls

$p$ value and respective OR (odds ratio) for differences in genotype frequencies between patients and controls

$C R C$ colorectal cancer, $W T$ wildtype, MUT mutant, WT/WT homozygous wild-type, WT/MUT heterozygous, MUT/MUT homozygous mutant, $O R$ odds ratio, $C I$ confidence interval

\begin{tabular}{llllll}
\hline Variant & \multicolumn{2}{l}{ Genotype } & & $p$ & OR (95\% CI) \\
\cline { 2 - 4 } & WT/WT & WT/MUT & MUT/MUT & & \\
\hline R702W & & & & & \\
CRC & 98 & 13 & 1 & 0.035 & $2.57(1.04-6.36)$ \\
Control & 144 & 8 & 0 & & \\
G908R & & & & 0.775 & $0.81(0.19-3.46)$ \\
CRC & 109 & 3 & 0 & & \\
Control & 147 & 5 & 0 & 0.749 & $0.68(0.06-7.55)$ \\
3020insC & 111 & 1 & 0 & & \\
CRC & 150 & 2 & 1 & 0.132 & $1.75(0.84-3.64)$ \\
Control & 94 & 17 & 0 & & \\
R702W/G908R/3020insC & 15 & & & \\
CRC & 137 & 15 & & & \\
Control & & & & & \\
\hline
\end{tabular}


without this familial aggregation $(11.8 \%$ vs. $16.8 \%$, respectively; $p=0.600$; OR, 0.66; 95\% CI, 0.14-3.17).

No associations were found between carriers of CARD15 mutations and clinical manifestations, neither with tumour stage, size, differentiation or location (Table 3). Similarly, we did not find any correlation between CARD15 mutations and survival or recurrence rates (Fig. 1).

In assessing genotype-phenotype correlations based only on the presence or absence of the CARD15 R702W variant, we detected a statistical significance for the same correlations, namely a significantly higher incidence of mutation in patients with CRC diagnosed under 60 years old and in female patients (Table 4 and Fig. 2).

\section{Discussion}

IBD-related cancer serves as an excellent model of inflammation-associated cancer and might also provide many important clues to understanding the pathogenesis of sporadic CRC [11]. Thus, because the normal colon is arguably in a continual state of low-grade inflammation in response to its microbial flora, it is reasonable to speculate that, apart from IBD-associated CRC, sporadic CRC might be consequence of bacteria-induced inflammation [8].

Polymorphisms in CARD15 have been associated with increased susceptibility to IBD, particularly to CD [21-25]. This discovery has led researchers to investigate the

Table 3 Clinicopathologic features of CRC patients with and without CARD15 mutations

\begin{tabular}{|c|c|c|c|c|c|}
\hline Variables & Total $n$ & Carriers $^{\mathrm{a}} \mathrm{n}(\%)$ & Non carriers $n$ & $p$ & OR $(95 \% \mathrm{CI})$ \\
\hline \multicolumn{6}{|l|}{ Gender } \\
\hline Female & 45 & $11(24.4)$ & 34 & \multirow[t]{2}{*}{0.048} & \multirow[t]{2}{*}{$2.77(0.98-7.82)$} \\
\hline Male & 67 & $7(10.4)$ & 60 & & \\
\hline \multicolumn{6}{|c|}{ Age at diagnosis ${ }^{b}$} \\
\hline$<60$ years & 35 & $10(28.6)$ & 25 & \multirow[t]{2}{*}{0.015} & \multirow[t]{2}{*}{$3.45(1.22-9.72)$} \\
\hline$\geq 60$ years & 77 & $8(10.4)$ & 69 & & \\
\hline \multicolumn{6}{|c|}{ Symptoms at diagnosis ${ }^{c}$} \\
\hline Yes & 97 & $16(16.5)$ & 81 & \multirow[t]{2}{*}{0.756} & \multirow[t]{2}{*}{$1.28(0.26-6.25)$} \\
\hline No & 15 & $2(13.3)$ & 13 & & \\
\hline \multicolumn{6}{|c|}{ Tumour location } \\
\hline Rectum & 52 & $8(15.4)$ & 44 & 0.854 (rectum vs. left + right) & $0.91(0.33-2.51)$ \\
\hline Left-colon & 29 & $6(20.7)$ & 23 & \multirow[t]{2}{*}{0.572 (rectum + left vs. right) } & \multirow[t]{2}{*}{$1.41(0.43-4.67)$} \\
\hline Right-colon & 31 & $4(12.9)$ & 27 & & \\
\hline \multicolumn{6}{|c|}{ Tumour size (mm) } \\
\hline$<30$ & 28 & $3(10.7)$ & 25 & \multirow[t]{2}{*}{0.373} & \multirow[t]{2}{*}{$0.55(0,15-2.07)$} \\
\hline$\geq 30$ & 84 & $15(17.9)$ & 69 & & \\
\hline \multicolumn{6}{|l|}{ Differentiation } \\
\hline Good & 84 & $14(16.7)$ & 70 & 0.766 (good vs. moderate+poor) & $1.20(0.36-4.00)$ \\
\hline Moderate & 24 & $4(16.7)$ & 20 & \multirow[t]{2}{*}{0.373 (good + moderate vs. poor $)$} & \multirow[t]{2}{*}{-} \\
\hline Poor & 4 & $0(0)$ & 4 & & \\
\hline \multicolumn{6}{|l|}{ T stage } \\
\hline 1 & 16 & $3(18.8)$ & 13 & 0.753 (T1 vs. $\mathrm{T} 2+\mathrm{T} 3+\mathrm{T} 4)$ & $1.25(0.32-4.91)$ \\
\hline 2 & 12 & $1(8.3)$ & 11 & 0.766 (T1+T2 vs. T3+T4) & $0.83(0.25-2.78)$ \\
\hline 3 & 66 & $12(18.2)$ & 54 & \multirow[t]{2}{*}{$0.532(\mathrm{~T} 1+\mathrm{T} 2+\mathrm{T} 3$ vs. T4) } & \multirow[t]{2}{*}{$1.64(0.34-7.85)$} \\
\hline 4 & 18 & $2(11.1)$ & 16 & & \\
\hline \multicolumn{6}{|l|}{$\mathrm{N}$ stage } \\
\hline 0 & 59 & $9(15.2)$ & 50 & \multirow[t]{2}{*}{0.804} & \multirow[t]{2}{*}{$0.88(0.32-2.41)$} \\
\hline 1 or 2 & 53 & $9(17.0)$ & 44 & & \\
\hline \multicolumn{6}{|l|}{ M stage } \\
\hline 0 & 91 & $15(16.5)$ & 76 & \multirow[t]{2}{*}{0.805} & \multirow[t]{2}{*}{$1.18(0.31-4.53)$} \\
\hline 1 & 21 & $3(14.3)$ & 18 & & \\
\hline
\end{tabular}

$C R C$ colorectal cancer, $O R$ odds ratio; $C I$ confidence interval

${ }^{\text {a }}$ Patients with CARD15 R702W, G908R or 3020 insC variants.

${ }^{\mathrm{b}}$ Patients were divided into early ( $<60$ years at diagnosis) and late ( $\geq 60$ years at diagnosis) onset groups as in previous studies [27, 29-31], to allow for comparison.

${ }^{\mathrm{c}}$ Symptoms: hematochezia, weight loss, anaemia, changes in bowel movement habits. 
Fig. 1 Cumulative survival and recurrence rates in colorectal cancer patients with and without CARD15 mutations

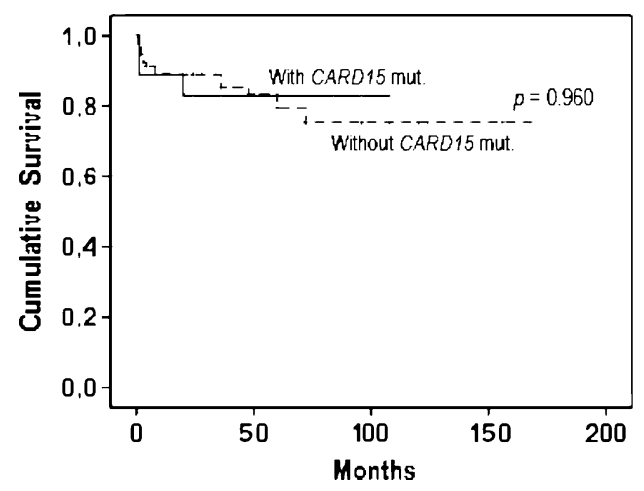

possible influence of this gene on the development of sporadic CRC, but the studies in this area have led to controversial results [26-32]. However, it has been demonstrated that there is regional heterogeneity within Europe in terms of the contribution of CARD15 variants to $\mathrm{CD}$ susceptibility, reflecting the effects of differing founder populations, and we can suppose that the same phenomenon can be seen in CRC [21, 24, 25, 33-35]. Given this data and knowing the high CRC incidence and mortality rate in our country, this paper aimed to clarify whether germline and/or somatic CARD15 mutations increase susceptibility to sporadic CRC in the Portuguese population and whether there are genotype-phenotype correlations in these patients.

We found that the frequency of R702W was significantly higher in the CRC patients than in the controls, whereas the frequency of G908R and 3020insC and the combined frequencies of the three key CARD15 mutations did not differ significantly between the two groups. These results agree with the findings of Roberts et al. in the New Zealand population where, in assessing the effect of each variant individually in a series of 133 CRC patients, only a significant association between $\mathrm{R} 702 \mathrm{~W}$ and $\mathrm{CRC}$ was detected $(\mathrm{OR}=2.30 ; 95 \% \mathrm{CI}, 1.1-5.0)$ [30]. However, in the New Zealand study, contrarily to our work, evidence for the association of the combined frequency of the three common CARD15 variants with the risk of CRC was obtained $(\mathrm{OR}=2.8 ; 95 \%$ CI, 1.5-5.4) [30]. Moreover, Papaconstantinou et al. [27] found that all the three major
CARD15 mutations were significantly elevated in Greek CRC patients $(\mathrm{OR}=4.06$; 95\% CI, 2.19-7.52), in Poland Kurzawski et al. [26] described an association between the CARD15 3020insC variant and $\mathrm{CRC}$ in patients aged over 50 at the time of diagnosis $(\mathrm{OR}=2.23 ; 95 \% \mathrm{CI}, 1.23-4.10)$ and recently a study conducted by Möckelmann et al. [32] found a significant association between $C A R D 15$ mutations and CRC susceptibility in a German cohort of patients aged under $50 \quad(p=0.038)$. In contrast, Alhopuro et al. and Tuupanen et al. found no link between CRC and any of the three main CARD15 mutations in a population-based series of 1042 Finnish CRC patients, although it must be borne in mind that the background frequency of CARD15 variants in the Scandinavian population is much lower [28, 29]. Likewise, Lakatos et al. observed similar variant allele frequencies in both the patient and control Hungarian groups [31].

As in $\mathrm{CD}$, where CARD15 mutations are associated with the early onset of disease, ileal localization and stricturing phenotype, it is possible that these mutations may also be predictive of the age of CRC presentation and of tumour behaviour [36-41]. Associations between CARD15 variants and specific clinicopathologic characteristics were observed in the Polish, Greek, New Zealand and German CRC cohorts [26, 27, 30, 32]. Within the Polish CRC cohort, the frequency of the 3020insC variant was found to be significantly elevated in patients aged over 50 at the time of diagnosis [26]. In the Greek cohort, the CARD15 variant carriers had more frequently advanced stage tumours [27].
Fig. 2 Cumulative survival and recurrence rates in colorectal cancer patients with and without CARD15 R702W variant
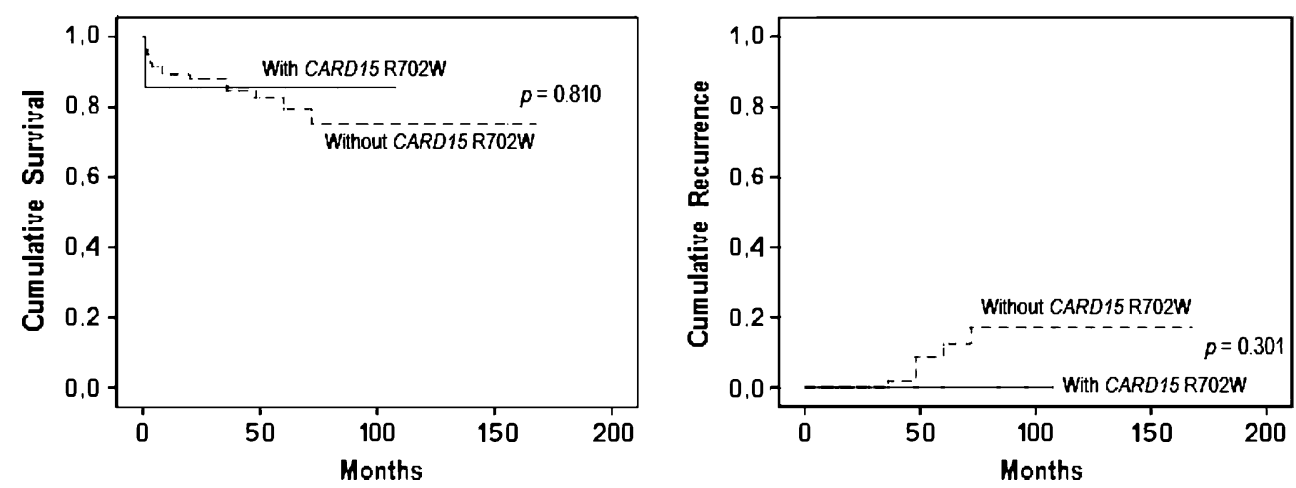
Table 4 Clinicopathologic features of CRC patients with and without CARD15 R702W variant

\begin{tabular}{|c|c|c|c|c|c|}
\hline Variables & Total $n$ & Carriers $^{\mathrm{a}} \mathrm{n}(\%)$ & Noncarriers $n$ & $p$ & OR $(95 \% \mathrm{CI})$ \\
\hline \multicolumn{6}{|l|}{ Gender } \\
\hline Female & 45 & $9(20.0)$ & 36 & \multirow[t]{2}{*}{0.049} & \multirow[t]{2}{*}{$3.10(0.96-9.97)$} \\
\hline Male & 67 & $5(7.5)$ & 62 & & \\
\hline \multicolumn{6}{|c|}{ Age at diagnosis ${ }^{\mathrm{b}}$} \\
\hline$<60$ years & 35 & $9(25.7)$ & 26 & \multirow[t]{2}{*}{0.004} & \multirow[t]{2}{*}{$4.99(1.53-16.25)$} \\
\hline$\geq 60$ years & 77 & $5(6.5)$ & 72 & & \\
\hline \multicolumn{6}{|c|}{ Symptoms at diagnosis ${ }^{\mathrm{c}}$} \\
\hline Yes & 97 & $12(12.4)$ & 85 & \multirow[t]{2}{*}{0.916} & \multirow[t]{2}{*}{$0.92(0.18-4.58)$} \\
\hline No & 15 & $2(13.3)$ & 13 & & \\
\hline \multicolumn{6}{|c|}{ Tumour location } \\
\hline Rectum & 52 & $4(7.7)$ & 48 & 0.152 (rectum vs. left + right $)$ & $0.42(0.12-1.42)$ \\
\hline Left-colon & 29 & $6(20.7)$ & 23 & \multirow[t]{2}{*}{0.936 (rectum+left vs. right) } & \multirow[t]{2}{*}{$0.95(0.28-3.29)$} \\
\hline Right-colon & 31 & $4(12.9)$ & 27 & & \\
\hline \multicolumn{6}{|c|}{ Tumour size (mm) } \\
\hline$<30$ & 28 & $2(7.1)$ & 26 & \multirow[t]{2}{*}{0.322} & \multirow[t]{2}{*}{$0.46(0.10-2.20)$} \\
\hline$\geq 30$ & 84 & $12(14.3)$ & 72 & & \\
\hline \multicolumn{6}{|l|}{ Diferentiation } \\
\hline Good & 84 & $11(13.1)$ & 73 & 0.741 (good vs. moderate + poor $)$ & $1.26(0.32-4.87)$ \\
\hline Moderate & 24 & $3(12.5)$ & 21 & \multirow[t]{2}{*}{0.441 (good + moderate vs. poor $)$} & \multirow[t]{2}{*}{-} \\
\hline Poor & 4 & $0(0)$ & 4 & & \\
\hline \multicolumn{6}{|l|}{ T stage } \\
\hline 1 & 16 & $1(6.3)$ & 15 & 0.414 (T1 vs. $\mathrm{T} 2+\mathrm{T} 3+\mathrm{T} 4)$ & $0.43(0.05-3.50)$ \\
\hline 2 & 12 & $0(0)$ & 12 & 0.099 (T1+T2 vs. T3+T4) & $0.20(0.03-1,62)$ \\
\hline 3 & 66 & $11(16.7)$ & 55 & \multirow[t]{2}{*}{$0.846(\mathrm{~T} 1+\mathrm{T} 2+\mathrm{T} 3$ vs. $\mathrm{T} 4)$} & \multirow[t]{2}{*}{$1.17(0.24-5.74)$} \\
\hline 4 & 18 & $2(11.1)$ & 16 & & \\
\hline \multicolumn{6}{|l|}{$\mathrm{N}$ stage } \\
\hline 0 & 59 & $8(13.6)$ & 51 & \multirow[t]{2}{*}{0.721} & \multirow[t]{2}{*}{$1.23(0.40-3.81)$} \\
\hline 1 or 2 & 53 & $6(11.3)$ & 47 & & \\
\hline \multicolumn{6}{|l|}{ M stage } \\
\hline 0 & 91 & $12(13.2)$ & 79 & \multirow[t]{2}{*}{0.647} & \multirow[t]{2}{*}{$1.44(0.30-7.00)$} \\
\hline 1 & 21 & $2(9.5)$ & 19 & & \\
\hline
\end{tabular}

$C R C$ colorectal cancer, $O R$ odds ratio, $C I$ confidence interval

${ }^{\text {a }}$ Patients with $C A R D 15 \mathrm{R} 702 \mathrm{~W}$ variant.

${ }^{\mathrm{b}}$ Patients were divided into early ( $<60$ years at diagnosis) and late ( $\geq 60$ years at diagnosis) onset groups as in previous studies [27, 29-31], to allow for comparison

${ }^{\mathrm{c}}$ Symptoms: hematochezia, weight loss, anaemia, changes in bowel movement habits.

In the New Zealand study, female CRC patients were far less likely to carry a CARD15 mutation than their male counterparts [30]. Finally, in the German cohort, the frequency of $\mathrm{R} 702 \mathrm{~W}$ and the combined frequency of genotypes harbouring R702W, G908R or 3020insC were found to be significantly higher in patients $\leq 50$ years old at the time of the CRC diagnosis [32]. In our CRC cohort we found a significantly higher incidence of CARD15 mutations in patients diagnosed under 60 years old and in female patients, and we did not detect any differences in tumour behaviour between individuals who carried CARD15 mutations and those who had a wild-type CARD15 genotype. These data suggest that also with regard to genotype-phenotype correlations there is regional heterogeneity.

As in other studies, we found no association between CARD15 mutations and a familial aggregation of CRC [26, 28, 29].

In order to assess the possible contribution of loss of the wild-type CARD15 allele in 3020insC-related tumourigenesis, Alhopuro et al. sequenced the tumour tissue DNA of all the patients heterozygous for the CARD15 3020insC variant in normal tissue DNA [28]. They found loss of heterozygosity in only one of the 33 heterozygous patients and concluded that there was no evidence of contribution of loss of the wild-type CARD15 allele in the 
CRC carcinogenesis [28]. These results do not allow any conclusions to be drawn as to whether CARD15 somatic mutations are involved in the predisposition to CRC. This assessment also implies the genotyping of tumour tissue DNA in patients without CARD15 mutations in nonneoplastic DNA. In our work, the entire CARD15 genotypic agreement between blood and neoplastic samples suggests that CRC susceptibility associated with CARD15 variants is linked to germline mutations without the apparent participation of somatic mutations. To our knowledge, this is the only study involving research of CARD15 variants in both neoplastic and non-neoplastic DNA within a random group of CRC patients. Thus, it is also the first study suggesting that only CARD 15 germline mutations are involved in the increased susceptibility to CRC associated with this gene. This important and interesting topic needs further confirmation in different and larger samples of CRC patients.

The potential limitations of our study should be mentioned. Firstly, the size of the study population is relatively small. Secondly, as CARD15 is associated with immune modulation, we cannot rule out the fact that other genetic factors involved in the immune response or implicated in the control of inflammatory response may also contribute to the risk of disease. Thirdly, the potential effect of environmental factors and/or their interaction with CARD15 mutations have not been evaluated. Finally, this work was performed in a teaching and referral hospital and therefore our results may not be applicable to institutions with different patient populations.

Our findings suggest that genetic variability within CARD15 may be one of the factors contributing to the elevated risk of CRC observed in the Western world, and particularly in Portugal. However, the available results show regional heterogeneity in terms of the contribution of CARD15 variants to CRC susceptibility. Moreover, environmental factors and additional genetic factors vary greatly between populations, and genetic polymorphisms are thought to play a role in determining how individuals respond at cellular level to various environmental factors [42]. Thus, further data from different and larger populations is needed to determine whether CARD15 mutations lead to a predisposition to CRC and, if so, to identify the additional determinants necessary for this increased susceptibility. A thorough investigation of these issues may improve screening recommendations, could shed light on the mechanisms of sporadic malignancy initiation and progression and might be critical to the development of pharmaceutical agents for cancer chemoprevention. Additionally, further research is needed in order to clarify the potential role of CARD15 mutations in cancer pathogenesis and pathophysiology.

In conclusion, our study suggests that the CARD15 $\mathrm{R} 702 \mathrm{~W}$ variant might be a predisposing factor to sporadic
CRC in the Portuguese population, particularly for those aged under 60 and in female patients. Additionally, this is the first study to hint that this susceptibility to CRC is linked only to germline CARD15 mutations. Nevertheless, CARD15 mutations do not appear to influence the pathological expression of CRC in Portuguese patients. Regional heterogeneity within the CARD15 genotype in CRC patients shows the importance of the genetic assessment and evaluation of its correlation with the phenotype in different populations. Additional research, using larger patient groups as well as other populations, is required in order to unequivocally determine the role of CARD 15 variants in CRC risk and carcinogenesis.

Conflicts of interest The authors declare that they have no conflict of interest.

\section{References}

1. Boyle P, Langman JS (2000) ABC of colorectal cancer: epidemiology. BMJ 321:805-808

2. Parkin DM (2001) Global cancer statistics in the year 2000. Lancet Oncol 2:533-543

3. Ferlay J, Autier P, Boniol M et al (2007) Estimates of the cancer incidence and mortality in Europe in 2006. Ann Oncol 18:581592

4. Tejpar S, Van Cutsem E (2002) Molecular and genetic defects in colorectal tumorigenesis. Best Pract Res Clin Gastroenterol $16: 171-185$

5. Lakatos PL, Lakatos L (2006) Current concepts in the genetics of hereditary and sporadic colorectal cancer and the role of genetics in clinical practice: sporadic and IBD-associated colorectal tumors, significance of genetic tests in diagnosis, prognosis and assessment of chemotherapy outcome. Orv Hetil 147:449-455

6. Popat S, Wort R, Houlston RS (2006) Inter-relationship between microsatellite instability, thymidylate synthase expression, and p53 status in colorectal cancer: implications for chemoresistance. BMC Cancer 6:150

7. Fuszek P, Lakatos P, Tabak A et al (2004) Relationship between serum calcium and CA 19-9 levels in colorectal cancer. World J Gastroenterol 10:1890-1892

8. Rhodes JM, Campbell BJ (2002) Inflammation and colorectal cancer: IBD-associated and sporadic cancer compared. Trends Mol Med 8:10-16

9. Coussens LM, Werb Z (2002) Inflammation and cancer. Nature 420:860-867

10. Williams MP, Pounder RE (1999) Helicobacter pylori: from the benign to the malignant. Am J Gastroenterol 94:S11-S16

11. Munkholm P (2003) Review article: the incidence and prevalence of colorectal cancer in inflammatory bowel disease. Aliment Pharmacol Ther 18:1-5

12. Higaki S, Akazawa A, Nakamura H et al (1999) Metaplastic polyp of the colon develops in response to inflammation. J Gastroenterol Hepatol 14:709-714

13. Eberhart CE, Coffey RJ, Radhika A et al (1994) Up-regulation of cyclooxygenase 2 gene expression in human colorectal adenomas and adenocarcinomas. Gastroenterology 107:1183-1188

14. Phoa N, Epe B (2002) Influence of nitric oxide on the generation and repair of oxidative DNA damage in mammalian cells. Carcinogenesis 23:469-475 
15. Jackson AL, Loeb LA (2001) The contribution of endogenous sources of DNA damage to the multiple mutations in cancer. Mutat Res 477:7-21

16. Moore MA (2002) Cytokine and chemokine networks influencing stem cell proliferation, differentiation, and marrow homing. J Cell Biochem 38:29-38

17. Nakajima N, Kuwayama H, Ito Y et al (1997) Helicobacter pylori, neutrophils, interleukins, and gastric epithelial proliferation. J Clin Gastroenterol 25:S198-S202

18. Jackson JR, Seed MP, Kircher CH et al (1997) The codependence of angiogenesis and chronic inflammation. FASEB J 11:457-465

19. Dubé C, Rostom A, Lewin G et al (2007) The use of aspirin for primary prevention of colorectal cancer: a systematic review prepared for the U.S. preventive services task force. Ann Intern Med 146:365375

20. Orlando RC (2002) Mechanisms of epithelial injury and inflammation in gastrointestinal diseases. Rev Gastroenterol Disord 2:S2-S8

21. Hugot JP, Chamaillard M, Zouali H et al (2001) Association of NOD2 leucine-rich repeat variants with susceptibility to Crohn's disease. Nature 411:599-603

22. Ogura Y, Bonen DK, Inohara N et al (2001) A frameshift mutation in NOD2 associated with susceptibility to Crohn's disease. Nature 411:603-606

23. Lesage S, Zouali H, Cézard JP et al (2002) CARD15/NOD2 mutational analysis and genotype-phenotype correlation in 612 patients with inflammatory bowel disease. Am J Hum Genet 70:845-857

24. Hampe J, Cuthbert A, Croucher PJ et al (2001) Association between insertion mutation in NOD2 gene and Crohn's disease in German and British populations. Lancet 357:1925-1928

25. Heliö T, Halme L, Lappalainen M et al (2003) CARD15/NOD2 gene variants are associated with familially occurring and complicated forms of Crohn's disease. Gut 52:558-562

26. Kurzawski G, Suchy J, Kładny J et al (2004) The NOD2 3020insC mutation and the risk of colorectal cancer. Cancer Res 64:1604-1606

27. Papaconstantinou I, Theodoropoulos G, Gazouli M et al (2005) Association between mutations in the CARD15/NOD2 gene and colorectal cancer in a Greek population. Int J Cancer 114:433-435

28. Alhopuro P, Ahvenainen T, Mecklin JP et al (2004) NOD2 3020 insC alone is not sufficient for colorectal cancer predisposition. Cancer Res 64:7245-7247

29. Tuupanen S, Alhopuro P, Mecklin JP et al (2007) No evidence for association of NOD2 R702W and G908R with colorectal cancer. Int J Cancer 121:76-79
30. Roberts RL, Gearry RB, Allington MD et al (2006) Caspase recruitment domain-containing protein 15 mutations in patients with colorectal cancer. Cancer Res 66:2532-2535

31. Lakatos PL, Hitre E, Szalay F et al (2007) Common NOD2/ CARD15 variants are not associated with susceptibility or the clinicopathologic characteristics of sporadic colorectal cancer in Hungarian patients. BMC Cancer 7:54

32. Möckelmann N, von Schönfels W, Buch S et al (2009) Investigation of innate immunity genes CARD4, CARD 8 and $C A R D 15$ as germline susceptibility factors for colorectal cancer. BMC Gastroenterol 9:79

33. Arnott ID, Nimmo ER, Drummond HE et al (2004) NOD2/ CARD15, TLR4 and CD14 mutations in Scottish and Irish Crohn's disease patients: evidence for genetic heterogeneity within Europe? Genes Immun 5:417-425

34. Croucher PJ, Mascheretti S, Hampe J et al (2003) Haplotype structure and association to Crohn's disease of CARD15 mutations in two ethnically divergent populations. Eur J Hum Genet 11:6-16

35. Gaya DR, Russell RK, Nimmo ER et al (2006) New genes in inflammatory bowel disease: lessons for complex diseases? Lancet 367:1271-1284

36. Henckaerts L, Van Steen K, Verstreken I et al (2009) Genetic risk profiling and prediction of disease course in Crohn's disease patients. Clin Gastroenterol Hepatol 7:972-980

37. Annese V, Lombardi G, Perri F et al (2005) Variants of CARD15 are associated with an aggressive clinical course of Crohn's disease-an IG-IBD study. Am J Gastroenterol 100:84-92

38. Hampe J, Grebe J, Nikolaus S et al (2002) Association of NOD2 (CARD 15) genotype with clinical course of Crohn's disease: a cohort study. Lancet 359:1661-1665

39. Abreu MT, Taylor KD, Lin YC et al (2002) Mutations in NOD2 are associated with fibrostenosing disease in patients with Crohn's disease. Gastroenterology 123:679-688

40. Economou M, Trikalinos TA, Loizou KT et al (2004) Differential effects of NOD2 variants on Crohn's disease risk and phenotype in diverse populations: a metaanalysis. Am J Gastroenterol 99:23932404

41. Radford-Smith G, Pandeya N (2006) Associations between NOD2/CARD15 genotype and phenotype in Crohn's diseaseare we there yet? World J Gastroenterol 12:7097-7103

42. Allen JI (1995) Molecular biology of colon polyps and colon cancer. Semin Surg Oncol 11:399-405 